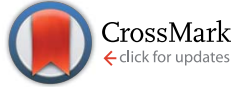

Cite this: RSC Adv., 2016, 6, 96015

www.rsc.org/advances

\title{
Correction: Electrochemical exfoliation of graphene sheets from a natural graphite flask in the presence of sulfate ions at different temperatures
}

\author{
Chien-Te Hsieh* and Jen-Hao Hsueh
}

Correction for 'Electrochemical exfoliation of graphene sheets from a natural graphite flask in the presence of sulfate ions at different temperatures' by Chien-Te Hsieh et al., RSC Adv., 2016, 6, 64826-64831.

In the original manuscript, an incorrect title for the manuscript was given. The correct title for the manuscript should be 'Electrochemical exfoliation of graphene sheets from a natural graphite electrode in the presence of sulfate ions at different temperatures'.

Several references were omitted from the reference section, and several citations in the Introduction section of the manuscript referred to the wrong references. The missing references have been added below; the reference numbers 1-4 refer to the new references given below, while the numbers 16, 17 and 34 refer to the references given in the original manuscript. The relevant sentences from the introduction are given below with the correct referencing:

The EE of graphite into GN with one or a few stacks of graphene-like sheets could be achieved using different types of electrolytes such as $\mathrm{LiCl}$ in propylene carbonate $(\mathrm{PC}),{ }^{16}\left(\mathrm{NH}_{4}\right)_{2} \mathrm{SO}_{4}$ aqueous solution, ${ }^{17} \mathrm{LiOH}$ molten salt, ${ }^{1} \mathrm{LiClO}{ }_{4}$ in $\mathrm{PC}^{2} \mathrm{LiCl}$ in dimethyl sulfoxide, ${ }^{3}$ and $\mathrm{H}_{2} \mathrm{SO}_{4}$ aqueous solution. ${ }^{34,4}$

This is because $\mathrm{SO}_{4}{ }^{2-}$ ions tend to intercalate defective sites at edges or grain boundaries of graphite, originated from the electrolysis of water. ${ }^{34}$ This superior efficiency can be attributed to a lower reduction potential of $\mathrm{SO}_{4}{ }^{2-}$ ions $(+0.20 \mathrm{~V})$ to enable release of $\mathrm{SO}_{2}$ gas and anion depolarization, ${ }^{17,4}$ causing the widening of interlayer distance of graphite.

The Royal Society of Chemistry apologises for these errors and any consequent inconvenience to authors and readers.

\section{References}

1 H. Huang, X. Yang, X. Tao, J. Du, J. Fang, Y. Gan and W. Zhang, J. Mater. Chem., 2012, 22, 10452-10456.

2 Y. L. Zhong and T. M. Swager, J. Am. Chem. Soc., 2012, 134, 17896-17899.

3 A. M. Abdelkader, I. A. Kinloch and R. A. W. Dryfe, ACS Appl. Mater. Interfaces, 2014, 6, 1632-1639.

4 K. Parvez, R. Li, S. R. Puniredd, Y. Hernandez, F. Hinkel, S. Wang, X. Feng and K. Mullen, ACS Nano, 7, 3598-3606. 